ORIGINAL ARTICLE

\title{
Cadence selection affects metabolic responses during cycling and subsequent running time to fatigue
}

\author{
F Vercruyssen, R Suriano, D Bishop, C Hausswirth, J Brisswalter
}

Br J Sports Med 2005;39:267-272. doi: 10.1136/bjsm.2004.011668

See end of article for authors' affiliations

.....................

Correspondence to: Dr Vercruyssen,

Department of Sport Ergonomics and Performance, University of Toulon-Var, BP 132 , 83957 La Garde cedex, France; vercruyssen@ univ-tln.fr

Accepted 6 April 2004

\begin{abstract}
Objectives: To investigate the effect of cadence selection during the final minutes of cycling on metabolic responses, stride pattern, and subsequent running time to fatigue.

Methods: Eight triathletes performed, in a laboratory setting, two incremental tests (running and cycling) to determine peak oxygen uptake ( $\mathrm{VO}_{2}$ PEAK) and the lactate threshold (LT), and three cycle-run combinations. During the cycle-run sessions, subjects completed a 30 minute cycling bout $(90 \%$ of LT) at (a) the freely chosen cadence (FCC, $94(5) \mathrm{rpm})$, (b) the FCC during the first 20 minutes and FCC $-20 \%$ during the last 10 minutes (FCC $-20 \%, 74(3) \mathrm{rpm})$, or (c) the FCC during the first 20 minutes and $\mathrm{FCC}+20 \%$ during the last 10 minutes $(F C C+20 \%, 109(5) \mathrm{rpm})$. After each cycling bout, running time to fatigue $\left(\mathrm{T}_{\max }\right)$ was determined at $85 \%$ of maximal velocity.

Results: A significant increase in $\mathrm{T}_{\max }$ was found after $\mathrm{FCC}-20 \%$ (894 (199) seconds) compared with FCC and $\mathrm{FCC}+20 \%$ (651 (212) and 624 (214) seconds respectively). $\mathrm{VO}_{2}$, ventilation, heart rate, and blood lactate concentrations were significantly reduced after 30 minutes of cycling at $\mathrm{FCC}-20 \%$ compared with $\mathrm{FCC}+20 \%$. A significant increase in $\mathrm{VO}_{2}$ was reported between the 3rd and 10th minute of all $\mathrm{T}_{\max }$ sessions, without any significant differences between sessions. Stride pattern and metabolic variables were not significantly different between $T_{\max }$ sessions.

Conclusions: The increase in $\mathrm{T}_{\max }$ after FCC $-20 \%$ may be associated with the lower metabolic load during the final minutes of cycling compared with the other sessions. However, the lack of significant differences in metabolic responses and stride pattern between the run sessions suggests that other mechanisms, such as changes in muscular activity, probably contribute to the effects of cadence variation on $T_{\max }$.
\end{abstract}

D uring triathlon racing (swim/cycle/run), the most critical and strategic aspect affecting overall performance is the change from cycling to running. ${ }^{1-6}$ These studies have attempted to identify aspects of cycling that may improve running performance in triathletes. Drafting has been shown to be a beneficial cycling strategy which results in an improved subsequent running performance in elite triathletes. ${ }^{4}$ More recently, the selection of cycling cadence during a cycle-run combination has been identified by researchers as an important variable that may affect overall performance. $^{1256}$ Cadence selection has been reported to influence metabolic responses, kinematic variables, and performance during a cycle-run session. However, the extent to which the cadence selection affects subsequent maximal running performance during a cycle-run combination remains unclear.

In a laboratory setting, Vercruyssen et al have shown that the adoption of a low cadence ( $73 \mathrm{rpm}$ ), corresponding to the energetically optimal cadence, reduced oxygen uptake $\left(\mathrm{VO}_{2}\right)$ during a cycle-run session, compared with the selection of higher cadences $(80-90 \mathrm{rpm})$. These authors suggested that the choice of a low cadence $(<80 \mathrm{rpm})$ before the cycle-run transition may be advantageous for the subsequent run. However, during field based investigations, Gottshall and Palmer $^{2}$ found an improved $3200 \mathrm{~m}$ track running performance after 30 minutes of cycling conducted at a high cadence (>100 rpm) compared with lower cadences (70-90 rpm) for a group of triathletes. It was suggested that the selection of a high cadence improved running performance through increased stride rate and running speed during the subsequent run. In contrast, Bernard et $a l^{6}$ showed no effect of cycling cadence (60-100 rpm) and stride rate on a subsequent $3000 \mathrm{~m}$ running performance. These conflicting results indicate the difficulty of predicting the optimal cadence selection for a cycle-run session in trained triathletes.
In most of the above experiments, the triathletes were required to cycle at either an imposed cadence (range 60$110 \mathrm{rpm}$ ) or a freely chosen cadence (range 80-90 rpm) which remained constant for the entire 30 minutes of the cycle bout. This lack of cadence variation does not reproduce race situations, during which the cadence may vary considerably especially before the cycle-run transition. ${ }^{1}$ Many triathletes attempt to optimise the change from cycling to running by selecting high cadences ( $>100 \mathrm{rpm}$ ) during the final kilometres of cycling. ${ }^{126}$ Another strategy, however, may be the selection of a low cadence ( $\sim 75 \mathrm{rpm})$ before the cycle-run transition, in order to conserve energy for the subsequent run. ${ }^{4}$ To our knowledge, no data are available on cadence changes during the last few minutes before the cycle-run transition and its effects on subsequent running performance.

Therefore the aim of this investigation was to examine, in a laboratory setting, the effect of cadence variations during the final 10 minutes of cycling on metabolic responses, stride pattern, and subsequent running time to fatigue in triathletes.

\section{METHODS \\ Participants}

Eight experienced male triathletes currently in training volunteered to take part in this experiment. All had regularly competed in triathlon racing at either sprint $(0.750 \mathrm{~km}$ swim/ $20 \mathrm{~km}$ cycle $/ 5 \mathrm{~km}$ run) or Olympic distances ( $1.5 \mathrm{~km}$ swim/ $40 \mathrm{~km}$ cycle $/ 10 \mathrm{~km}$ run) for at least five years. Mean (SD) training distances a week were $11.1(2.2) \mathrm{km}$ in swimming, $285.7(90.0) \mathrm{km}$ in cycling, and 42.1 (12.9) km in running.

Abbreviations: $\mathrm{FCC}$, freely chosen cadence; $\mathrm{HR}$, heart rate; $\left[\mathrm{La}^{-}\right]$, lactate concentration; $L T$, lactate threshold; $\mathrm{P}_{\text {max }}$, maximal power output; $\mathrm{V}_{\text {max }}$, maximal running speed; $\mathrm{VE}$, minute ventilation; $\mathrm{VO}_{2}$, oxygen uptake; $\mathrm{VO}_{2} \mathrm{PEAK}$, peak oxygen uptake; $\mathrm{VO}_{2 \mathrm{SC}}, \mathrm{VO}_{2}$ slow component 
Table 1 Peak exercise responses of triathletes

\begin{tabular}{lll}
\hline Variable & Cycling & Running \\
\hline $\mathrm{VO}_{2}$ PEAK $(\mathrm{ml} / \mathrm{min} / \mathrm{kg})$ & $67.6(3.6)$ & $68.9(4.6)$ \\
$\mathrm{VO}_{2}$ PEAK $(\mathrm{l} / \mathrm{min})$ & $4.9(0.4)$ & $5.0(0.5)$ \\
$\mathrm{VO}_{2}$ at $\mathrm{LT}(\mathrm{l} / \mathrm{min})$ & $3.8(0.4)$ & $4.4(0.5)^{*}$ \\
$\mathrm{HR}_{\text {peak }}($ beats $/ \mathrm{min})$ & $176(8)$ & $182(10)^{*}$ \\
{$\left[\mathrm{La}^{-}\right]_{\text {peak }}(\mathrm{mmol} / \mathrm{l})$} & $14.2(2.1)$ & $10.4(3.1)^{*}$ \\
$\mathrm{P}_{\text {max }}(\mathrm{W}) / \mathrm{V}_{\max }(\mathrm{km} / \mathrm{h})$ & $395(34)$ & $19.5(0.9)^{*}$ \\
\hline
\end{tabular}

Values are mean (SD).

*Significantly different from running $(p<0.05)$.

$\mathrm{VO}_{2} \mathrm{PEAK}$, peak oxygen uptake; $\mathrm{LT}$, lactate threshold; $\mathrm{HR}_{\text {peak, }}$ peak heart rate; $\left[\mathrm{La}^{-}\right]_{\text {peak, }}$ peak blood lactate concentration; $P_{\max }$, maximal power output; $V_{\max }$ maximal running speed.

Mean (SD) age of the subjects was 28.9 (7.4) years. Their mean (SD) height and body mass were $178.3(5.7) \mathrm{cm}$ and $73.3(6.0) \mathrm{kg}$ respectively. The test procedures were approved by the Human Rights Committee of the University of Western Australia. Each triathlete carried out, in a laboratory setting $\left(20-22^{\circ} \mathrm{C}, 40-60 \%\right.$ relative humidity, $740-760 \mathrm{~mm} \mathrm{Hg}$ pressure), five test sessions at the same time of day separated by a rest period of at least 48 hours.

\section{Maximal tests}

Two incremental tests were used to determine peak oxygen uptake $\left(\mathrm{VO}_{2}\right.$ PEAK$)$, maximal power output $\left(\mathrm{P}_{\max }\right)$, maximal running speed $\left(\mathrm{V}_{\max }\right)$, and lactate threshold (LT). Subjects performed cycling bouts on a racing bicycle mounted on a stationary turbo-trainer system. Variations in power output were measured using a "professional" SRM crankset system (Schoberer Rad Messtechnick, Fuchsend, Germany) previously validated in a protocol comparison using a motor driven friction brake. ${ }^{7}$ Running bouts were performed on a motorised treadmill situated next to the cycle turbo-trainer.

For cycling, the test bout began at an initial workload of $100 \mathrm{~W}$ for three minutes, after which the power output was increased by $40 \mathrm{~W}$ every three minutes until exhaustion. For the treadmill test, the initial running speed was fixed at $9 \mathrm{kph}$, with an increase in velocity of $1.5 \mathrm{kph}$ every three minutes. For both cycling and running tests, there was a one minute rest period between each increment for the sampling of capillary blood $(35 \mu \mathrm{l})$ from a hyperaemic earlobe. Blood samples were collected to determine plasma lactate concentration $\left(\left[\mathrm{La}^{-}\right]\right)$using a blood gas analyser (ABL 625; Radiometer Medical A/S, Copenhagen, Denmark).

During these tests, $\mathrm{VO}_{2}$, minute ventilation (VE), and respiratory exchange ratio were continuously recorded every 15 seconds using Ametek gas analysers (SOV S-3A and COV CD3A; Pittsburgh, Pennsylvania, USA). The four highest consecutive $\mathrm{VO}_{2}$ values were summed to determine $\mathrm{VO}_{2}$ PEAK. $^{8}$ $\mathrm{P}_{\max }$ and $\mathrm{V}_{\max }$ were calculated as the average power output and running speed in the last three minutes completed before exhaustion. Heart rate (HR) was monitored every 10 seconds during each experimental session using an electronic HR device with a chest electrode (Polar Vantage NV; Polar Electro Oy, Kempele, Finland). The LT calculated by the modified $\mathrm{D}_{\max }$ method was determined by the point on the polynomial regression curve that yielded the maximal perpendicular distance to the straight line formed by the lactate inflection point (first increase in lactate concentration above the resting level) and the final lactate point. ${ }^{8}$

\section{Cycle-run combinations}

All triathletes completed, in random order, three cycle-run sessions each composed of 30 minutes of cycling, on a cycle turbo-trainer, and a subsequent run to fatigue. A fan was used in front of the subject during these experimental sessions. Before each experimental condition, subjects
Table 2 Cadence and power output values during the three cycling bouts at different time periods: $3-5,20-22$, 28-30 min

\begin{tabular}{lll}
\hline Cycling bout & Cadence (rpm) & Power output (W) \\
\hline FCC $-20 \%$ & $93(5)$ & $264(30)$ \\
$3-5 \mathrm{~min}$ & $75(3)^{*} \dagger$ & $262(28)$ \\
$20-22 \mathrm{~min}$ & $74(4)^{*} \dagger$ & $262(25)$ \\
$28-30 \mathrm{~min}$ & $94(5)$ & $264(30)$ \\
FCC & $94(5) \dagger$ & $264(29)$ \\
$3-5 \mathrm{~min}$ & $95(5) \dagger$ & $265(30)$ \\
$20-22 \mathrm{~min}$ & & $263(30)$ \\
$28-30 \mathrm{~min}$ & $91(4)$ & $259(27)$ \\
FCC $+20 \%$ & $108(4)^{*} \dagger$ & $262(30)$ \\
$3-5$ min & $109(6)^{*} \dagger$ & \\
$20-22$ min & \\
$28-30$ min & \\
\hline & \\
Values are mean (SD). & \\
*Significantly different from the first 20 minutes, $\mathrm{p}<0.05$. \\
†Significantly different from the other conditions at the same time period, \\
p<0.05.
\end{tabular}

performed 15 minutes of warm up comprising 13 minutes at a low power output (100-130 W) and the last two minutes at the individual workload required during the cycle bout of cycle-run sessions. After two minutes of rest, each triathlete completed a cycle bout at $(a)$ the freely chosen cadence (FCC), (b) the FCC during the first 20 minutes and FCC $-20 \%$ during the last 10 minutes $($ FCC $-20 \%$ ), or (c) the FCC during the first 20 minutes and FCC+20\% during the last 10 minutes $(\mathrm{FCC}+20 \%)$. The $\mathrm{FCC} \pm 20 \%$ range has previously been used during a 30 minute cycling exercise in triathletes. ${ }^{10}$ Cycling bouts were performed at a power output corresponding to $90 \%$ of LT $(266$ (28) W) and represented an intensity close to that reported in previous studies of the relation between cycling cadence and running performance. ${ }^{56}$ FCC $-20 \%$ was chosen to replicate cadence values close to the energetically optimal cadence previously noted in triathletes, ${ }^{5}$ and FCC $+20 \%$ allowed us to reproduce cadence values close to those reported during cycling strategies before running. ${ }^{126}$ Cadence and power output were monitored using the SRM power meter during all cycling bouts. No feedback was given to the subjects on their FCC over the three conditions.

After each cycling bout, running time to fatigue $\left(\mathrm{T}_{\max }\right)$ was determined on the treadmill at a running speed corresponding to $85 \%$ of $\mathrm{V}_{\max }(>\mathrm{LT})$ for each athlete ( 16.7 (0.7) $\mathrm{kph}$ ). On the basis of previous experiments ${ }^{11}{ }^{12}$ and the completion of pilots tests, this running intensity was chosen to induce fatigue in less than 20 minutes. All subjects were given verbal encouragement throughout each trial. The $\mathrm{T}_{\max }$ was taken as the time at which the subject's feet left the treadmill as he placed his hands on the guardrails. The transition time between running and cycling was fixed at 45 seconds to reproduce the racing context. ${ }^{16}$

\section{Measurement of metabolic variables}

$\mathrm{VO}_{2}, \mathrm{VE}$, and $\mathrm{HR}$ were monitored and analysed during the following intervals: 3rd-5th minute of cycling bout (3$5 \mathrm{~min}), 20$ th-22nd minute (20-22 min), 28th-30th minute (28-30 min) and every minute during the running sessions. Five blood samples were collected at the following intervals: before the warm up, at 5, 20, and 30 minutes during cycling, and at the end of $\mathrm{T}_{\max }$.

\section{Measurement of kinematic variables}

Power output and cycling cadence were continuously recorded during the cycling bouts. For each running session, a $50 \mathrm{~Hz}$ digital camera was mounted on a tripod $4 \mathrm{~m}$ away from the motorised treadmill. Subsequently, the treadmill 
Table 3 Variations in mean oxygen uptake $\left(\mathrm{VO}_{2}\right)$, minute ventilation $(\mathrm{VE})$, heart rate $(\mathrm{HR})$, and blood lactate concentration ([ $\left.\left.\mathrm{La}^{-}\right]\right)$, during the three cycling bouts, at different time periods: $3-5,20-22,28-30 \mathrm{~min}$

\begin{tabular}{|c|c|c|c|c|}
\hline Cycling bout & $\mathrm{Vo}_{2}(\mathrm{ml} / \mathrm{kg} / \mathrm{min})$ & VE $(1 / \mathrm{min})$ & HR (beats/min) & {$\left[\mathrm{La}^{-}\right](\mathrm{mmol} / \mathrm{l})$} \\
\hline \multicolumn{5}{|l|}{ FCC $-20 \%$} \\
\hline $3-5 \min$ & $47.4(3.5)$ & $74.7(9.5)$ & $139(11)$ & $3.3(1.2)$ \\
\hline $20-22 \mathrm{~min}$ & $47.5(4.3)$ & $74.8(1.2)$ & $141(10)$ & $3.3(1.4)$ \\
\hline $28-30 \mathrm{~min}$ & $48.6(3.2)$ & $75.3(9.9)$ & $142(11)$ & $2.7(1.0)^{*} \dagger$ \\
\hline \multicolumn{5}{|l|}{ FCC } \\
\hline $3-5 \min$ & $47.3(4.4)$ & 74.7 (10.7) & $140(11)$ & $2.7(0.7)$ \\
\hline $20-22 \mathrm{~min}$ & $49.1(5.2)$ & $80.2(12.5)$ & $147(14)$ & $3.3(1.0)$ \\
\hline $28-30 \mathrm{~min}$ & $50.1(4.8)^{*}$ & 82.5 (12.6) & $150(14)^{*} \ddagger$ & $3.2(0.9) \S$ \\
\hline \multicolumn{5}{|l|}{$\mathrm{FCC}+20 \%$} \\
\hline $3-5 \min$ & $46.1(3.8)$ & $73.6(9.0)$ & $138(11)$ & $2.7(0.6)$ \\
\hline $20-22 \mathrm{~min}$ & 47.8 (3.8) & 79.5 (11.1) & 144 (12) & $2.9(0.6)$ \\
\hline $28-30 \mathrm{~min}$ & $51.2(4.5)^{\star} \ddagger$ & $89.0(12.4)^{*} \ddagger$ & $152(14)^{\star} \ddagger$ & $4.2(0.8)^{*}+\ddagger$ \\
\hline
\end{tabular}

Values are expressed as mean (SD).

*Significantly different from the 3-5 min interval, $\mathrm{p}<0.05$.

†Significantly different from the 20-22 min interval, $\mathrm{p}<0.05$.

$¥$ Significantly different from FCC-20\% at the same period, $p<0.05$.

§Significantly different from $\mathrm{FCC}+20 \%$ at the same period, $p<0.05$.

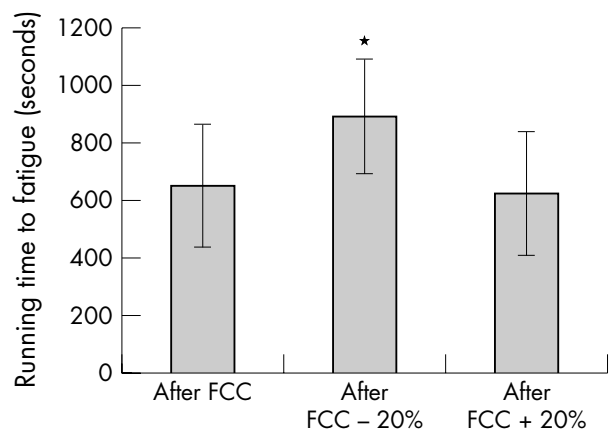

Figure 1 Running time to fatigue after the selection of various cycling cadences. Values are expressed as mean (SD). *Significantly different from the other sessions, $\mathrm{p}<0.05$.

speed and period between two ground contacts for the same foot were determined using a kinematic video analysis system (SiliconCoach Pro Version 6, Dunedin, New Zealand). From these values, stride pattern characteristicsthat is, stride rate $(\mathrm{Hz})$ and stride length $(\mathrm{m})$-were calculated every 30 seconds during the first five minutes and the last two minutes of the $\mathrm{T}_{\max }$ sessions.

\section{Statistical analysis}

All data are expressed as mean (SD). A two way variance analysis plan with repeated measures was performed to analyse the effects of cadence selection (FCC, FCC $-20 \%$, FCC $+20 \%$ ) and time during the cycle-run sessions using $\mathrm{VO}_{2}$, VE, HR, $\left[\mathrm{La}^{-}\right]$, stride rate, stride length, cadence and power output, as dependent variables. A Tukey post hoc test was used to determine any differences between the cycle-run combinations. Differences in $\mathrm{T}_{\max }$ obtained between the three experimental conditions were analysed by one way analysis of variance. A paired $t$ test was used to analyse differences in $\mathrm{VO}_{2}$ PEAK, $\mathrm{HR}_{\text {peak, }}$ and $\mathrm{VO}_{2}$ at LT between the two maximal tests. Statistical significance was set at $\mathrm{p}<0.05$.

\section{RESULTS}

\section{Maximal tests}

No significant differences in $\mathrm{VO}_{2}$ PEAK were observed between the sessions (table 1). However, $\mathrm{HR}_{\text {peak }}$ and $\mathrm{VO}_{2}$ at LT were significantly higher during running than during the maximal cycling bout $(+2.9 \%$ and $+15.8 \%$ respectively $)$.

\section{Cycling bouts of cycle-run sessions}

No significant variation in FCC was observed during the first 20 minutes of the three cycling bouts (table 2). In addition, mean power output values were not significantly different between the cycling bouts (264 (30), 263 (28), and 261 (29) W respectively for FCC, FCC $-20 \%$, and FCC $+20 \%$ ). These data show that subjects adhered to the experimental design with respect to the required power output-cadence combination.

A significant effect of exercise duration (between 3-5 and 28-30 min intervals) was observed on $\mathrm{VO}_{2}, \mathrm{VE}$, and $\mathrm{HR}$ during the FCC and FCC $+20 \%$ bouts whereas no significant variation in these metabolic variables was identified with exercise duration during the FCC $-20 \%$ condition (table 3 ). Moreover, mean $\mathrm{VO}_{2}, \mathrm{VE}$, and HR were significantly lower at FCC $-20 \%$ compared with FCC $+20 \%$ during the $28-30 \mathrm{~min}$ interval (respectively, $-5.3 \%,-18.2 \%$, and $-6.8 \%$ ). [ $\mathrm{La}^{-}$] was significantly higher during the $28-30$ min interval at FCC $+20 \%$ compared with FCC $(+31.2 \%)$ or FCC $-20 \%$ $(+55.5 \%)$.

\section{Running bouts of cycle-run sessions}

A significant increase in $\mathrm{T}_{\max }$ was observed only after the FCC $-20 \%$ modality when compared with both the FCC $+20 \%$ and FCC conditions $(+43.3 \%$ and $+37.3 \%$ respectively; fig 1$)$. $\mathrm{T}_{\max }$ values were 624 (214), 651 (212) and 894 (199) seconds after the FCC+20\%, FCC and FCC-20\% modalities respectively. A significant increase in $\Delta \mathrm{VO}_{2}$-that is, between the 3rd and 10th minute-was found during the $\mathrm{T}_{\max }$ completed after FCC $(+6.1 \%), \quad$ FCC $+20 \%(+6.7 \%)$, and FCC $-20 \%$ $(+6.5 \%)$ (table 4). However, mean $\mathrm{Vo}_{2}, \mathrm{VE}, \mathrm{HR}$, and $\left[\mathrm{La}^{-}\right]$ were not significantly different between the three $\mathrm{T}_{\max }$ sessions (table 4).

No significant difference in stride pattern was observed during the $\mathrm{T}_{\max }$ sessions whatever the prior cadence selection (fig 2). Mean stride rate ( $\mathrm{Hz}$ ) and stride length $(\mathrm{m})$ were 1.49 $(0.01)$ and $3.13(0.02), 1.48(0.01)$ and $3.13(0.03), 1.49$ $(0.01)$ and $3.15(0.02)$, during the $\mathrm{T}_{\max }$ sessions subsequent to the FCC, FCC $-20 \%$ and FCC $+20 \%$ bouts respectively.

\section{DISCUSSION}

The main findings of this investigation show a significant increase in $\mathrm{T}_{\max }$ when the final 10 minutes of cycling is performed at FCC $-20 \%$ (894 seconds) compared with FCC (651 seconds) and FCC+20\% (624 seconds). Several hypotheses are proposed to explain the differences in $\mathrm{T}_{\max }$ reported 
Table 4 Variations in mean oxygen uptake $\left(\mathrm{VO}_{2}\right), \Delta \mathrm{VO}_{2}(10-3 \mathrm{~min})$, minute ventilation $(\mathrm{VE})$, heart rate $(\mathrm{HR})$, and blood lactate concentration ([ $\left.\left.\mathrm{La}^{-}\right]\right)$during the three running sessions performed after cycling

\begin{tabular}{llll}
\hline Variable & Run after FCC-20\% & Run after FCC & Run after FCC+20\% \\
\hline $\mathrm{VO}_{2}(\mathrm{ml} / \mathrm{min} / \mathrm{kg})$ & $63.9(2.7)$ & $62.0(2.8)$ & $61.8(1.4)$ \\
$\mathrm{VO}_{2}(\mathrm{l} / \mathrm{min})$ & $4.72(0.4)$ & $4.59(0.4)$ & $4.56(0.3)$ \\
$\mathrm{VO}_{2}(10-3 \mathrm{~min})(\mathrm{ml} / \mathrm{min})^{*}$ & $291.3(126.5)$ & $269.9(123.5)$ & $291.3(114.5)$ \\
$\mathrm{VE}(\mathrm{l} / \mathrm{min})$ & $122.5(15.8)$ & $122.0(13.3)$ & $122.8(10.8)$ \\
$\mathrm{HR}($ beats $/ \mathrm{min})$ & $169(8)$ & $169(10)$ & $168(10)$ \\
{$\left[\mathrm{La}^{-}\right](\mathrm{mmol} / \mathrm{l})$} & $6.8(1.7)$ & $7.4(2.1)$ & $7.2(2.2)$ \\
\hline \\
Values are expressed as mean (SD). \\
*Significantly different between the 3rd and 10th minute of exercise, $\mathrm{p}<0.05$. \\
\hline
\end{tabular}

during the various cycle-run combinations for the group of triathletes.

A number of studies have analysed characteristics of cyclerun sessions in triathletes, with particular focus on physiological and biomechanical aspects during the subsequent run. ${ }^{1}$ For instance, during a running session after cycling, a substantial increase in energy cost, VE, and HR, and differences in muscle blood flow have been observed compared with an isolated run. ${ }^{1356}$ Moreover, variations in running kinematics such as stride rate, segmental angular position, and joint angle have been shown after a cycle bout. ${ }^{35}$ These running alterations, which have been linked to the effects of exercise duration and cycle-run transition, were reported during treadmill sessions conducted at a submaximal intensity and not during a high intensity running bout. In this study we investigated these effects at a high intensity close to a running speed previously observed during a short cycle-run combination in triathletes. ${ }^{6}$

\section{Metabolic hypotheses}

The $\mathrm{T}_{\max }$ values of this investigation are comparable to those previously reported during an exhaustive isolated run performed at an intensity corresponding to $85-90 \%$ $\mathrm{VO}_{2} \mathrm{MAX}^{11-13}$ It has previously been reported that metabolic and muscular factors are potential determinants of middle distance running performance and/or exhaustive treadmill sessions in trained subjects. ${ }^{14-18}$ With respect to metabolic factors, the improvement in $\mathrm{T}_{\max }$ observed after FCC $-20 \%$ may be related to changes in energy contribution. In support

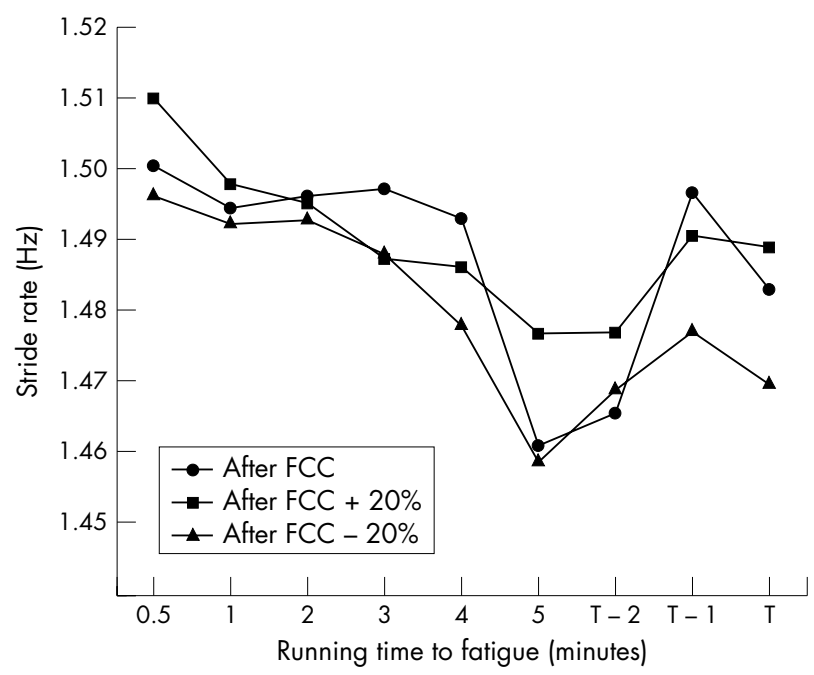

Figure 2 Variations in stride rate during the running time to fatigue after the selection of various cycling cadences. T, Stride rate obtained at $\mathrm{T}_{\max } ; \mathrm{T}-1$, stride rate obtained at $\mathrm{T}_{\max }-1 \mathrm{~min} ; \mathrm{T}-2$, stride rate obtained at $\mathrm{T}_{\max }-2 \mathrm{~min}$. of this hypothesis, it has been reported that the determinants of maximal performances in middle distance running may be linked to the energy requirement for a given distance and the maximal rate of metabolic energy output from the integrative contribution of aerobic and anaerobic systems. ${ }^{15} 18$ During submaximal and maximal running, the $\mathrm{VO}_{2}$ variation has been reported to reflect the relative contribution from the aerobic and anaerobic sources. ${ }^{15}$ In the context of a cycle-run session, Bernard et $a l^{6}$ have reported that triathletes were able to sustain a higher fraction of $\mathrm{VO}_{2} \mathrm{MAX}$ during a $3000 \mathrm{~m}$ track run performed after cycling at $60 \mathrm{rpm}$ than during cycling at 80 and $100 \mathrm{rpm}$. These authors suggested that a greater contribution of the aerobic component, during running after the choice of a low cadence, may delay fatigue for longer running distances. In this investigation, the analysis of $\mathrm{VO}_{2}$ may also provide information on possible changes in aerobic contribution during high intensity running. Given the range of $\mathrm{T}_{\max }$ values, the metabolic variables were analysed during the first 10 minutes of each running session, corresponding approximately to the mean $\mathrm{T}_{\max }$ values reported after the FCC and FCC $+20 \%$ modalities (fig 1). The evaluation of this time interval indicates no significant differences in $\mathrm{VO}_{2}$ between the $T_{\max }$ sessions, suggesting that the determination of $\mathrm{T}_{\max }$ in this study was not affected by changes in metabolic energy from the aerobic or anaerobic systems.

There was, however, a significant increase in $\mathrm{Vo}_{2}$ between the $3 \mathrm{rd}$ and 10th minute $(6.1-6.7 \%)$ during the three $\mathrm{T}_{\max }$ sessions, regardless of the prior experimental condition (table 4). During exercise lasting less than 15 minutes, the continual rise in $\mathrm{VO}_{2}$ beyond the 3rd minute has been termed the $\mathrm{VO}_{2}$ slow component $\left(\mathrm{VO}_{2 \mathrm{SC}}\right) .^{511}{ }^{1920}$ The occurrence of a $\mathrm{VO}_{2 \mathrm{SC}}$ is classically observed during heavy running and cycling exercises associated with a sustained lactic acidosis-that is, above the LT. ${ }^{192122}$ Postulated mechanisms responsible for this $\mathrm{VO}_{2 \mathrm{SC}}$ include rising muscle temperature $\left(Q_{10}\right.$ effect), cardiac and ventilatory muscle work, lactate kinetics, catecholamines, and recruitment of less efficient type II muscle fibres. ${ }^{20}$ Within this framework, Yano et al ${ }^{23}$ suggested that muscular fatigue may be one of the factors that produce the development of a $\mathrm{VO}_{2 \mathrm{SC}}$ during high intensity cycling exercise.

However, several investigators have examined the influence of prior exercise on the $\mathrm{VO}_{2}$ response during subsequent exercise. ${ }^{24-26}$ Burnley et al ${ }^{24}$ showed that the magnitude of $\mathrm{VO}_{2}$ kinetics during heavy exercise was affected only by a prior bout of heavy exercise. On the basis of similar results, it has been suggested that, during successive bouts of heavy exercise, muscle perfusion and/or $\mathrm{O}_{2}$ off loading at the muscle may be improved, resulting in changes in $\mathrm{VO}_{2}$ kinetics during the second bout of exercise. ${ }^{25}{ }^{26}$ In addition, changes in the $\mathrm{VO}_{2}$ response may be accentuated by the manipulation of cadence during an isolated cycling bout. ${ }^{27}$ Gotshall et al $^{27}$ showed an increase in muscle blood flow and a decrease in systemic vascular resistance with increasing cadence (from 


\section{What is already known on this topic}

Various characteristics of cycle-run sessions in triathletes have been studied, with particular focus on physiological and biomechanical aspects during the subsequent run. During a running session after cycling, a substantial increase in energy cost, minute ventilation, and heart rate, and differences in muscle blood flow have been observed compared with an isolated run. Moreover, variations in running kinematics such as stride rate, segmental angular position, and joint angle have been shown after a cycle bout.

70 to $110 \mathrm{rpm}$ ). These previous experimental designs, based on the characteristics of combined and isolated exercises, are similar to the current one and suggest that cadence selection may affect blood flow and hence the $\mathrm{VO}_{2}$ response during a subsequent run. For instance, the increased muscle blood flow at high cycling cadence ${ }^{27}$ during a prior cycle bout could attenuate the magnitude of $\mathrm{VO}_{2} \mathrm{SC}$ during subsequent running.

In contrast with these earlier studies, the $\mathrm{VO}_{2}$ sc values of this investigation were not significantly different between trials during the first 10 minutes of exercise between the $T_{\max }$ sessions. This was observed despite differences in metabolic load and cadence selection during the previous cycling bouts. These results indicate that the adoption of FCC $-20 \%$ is associated with a reduction in metabolic load with exercise duration, but does not affect the $\mathrm{VO}_{2 \mathrm{SC}}$ during the subsequent run. For instance, the selection of FCC $-20 \%$ is associated with a significant reduction in $\mathrm{VO}_{2}(-5.3 \%)$, VE $(-18.2 \%)$, $\mathrm{HR}(-6.8 \%)$, and $\left[\mathrm{La}^{-}\right](-55.5 \%)$ during the final 10 minutes of cycling compared with FCC $+20 \%$, without any significant changes in $\mathrm{VO}_{2 \mathrm{SC}}$ during subsequent running between the two conditions. This suggests that the chosen cadences do not affect the $\mathrm{VO}_{2}$ responses during the subsequent run and also that the occurrence of a $\mathrm{VO}_{2 \mathrm{SC}}$ does not contribute to the differences in $\mathrm{T}_{\max }$ found in this study. This is consistent with previous research on trained subjects. ${ }^{12}$

\section{Muscular and stride pattern hypotheses}

Although we conducted no specific analysis of muscular parameters, an attractive hypothesis to explain the differences in $\mathrm{T}_{\max }$ between conditions is that they are due to differences in the muscular activity or fatigue state during cycle-run sessions. Muscular contractions differ during cycling and running. Cycling is characterised by longer phases of concentric muscular contraction, whereas running involves successive phases of eccentric-concentric muscular action. ${ }^{28}$ Muscle activity during different modes of contraction can be assessed from the variation in the electromyographic signal. In integrated electromyography based investigations, it has been shown that muscles such as the gastrocnemius, soleus, and vastus lateralis are substantially activated during running. ${ }^{14}{ }^{17} 28$ Any alterations in the contractile capability of these muscles may have affected the ability to complete a longer $\mathrm{T}_{\max }$ during the cycle-run sessions in this study.

Furthermore, many studies have reported substantial changes in muscular activity during isolated cycling exercises, especially when cadence is increased or decreased. ${ }^{29-32}$ With respect to the cycle-run combination, the manipulation of cadence may accentuate modifications in muscular activity during cycling and influence the level of fatigue during a subsequent run. Marsh and Martin ${ }^{30}$ showed a linear increase in electromyographic activity of the gastrocnemius and vastus lateralis muscles when cadences increased from 50
What this study adds

This study shows that the choice of a low cadence during the final minutes of cycling improves subsequent running time to fatigue.

to $110 \mathrm{rpm}$. Although activity of the gastrocnemius muscle has been shown to increase considerably more than the soleus muscle as cadence is increased, ${ }^{30}{ }^{31}$ Ericson et al ${ }^{29}$ have also reported a significant increase in soleus muscle activity with the selection of high cadences. These results from isolated cycling exercises conducted in a state of non-fatigue suggest that, during the last 10 minutes of the cycling bout of our study, there was greater recruitment of the vastus lateralis, gastrocnemius, and soleus muscles after cycling at higher cadences. This may have resulted in an increase in fatigue of these muscles, which are substantially activated during subsequent running. In contrast, the lower activity of the vastus lateralis, gastrocnemius, and soleus muscles after the FCC $-20 \%$ condition may have reduced the fatigue experienced during cycling and resulted in improved utilisation of these muscles during the subsequent run. This may have contributed to the observed increase in $\mathrm{T}_{\max }$ for this condition. Nevertheless, Lepers et $a l^{10}$ suggested that the neuromuscular fatigue observed after 30 minutes of cycling was attributable to both central and peripheral factors but was not influenced by the pedalling rate in the range FCC $\pm 20 \%$. In this earlier study, the selected power outputs $(>300 \mathrm{~W})$ for all cadence conditions were significantly higher than those used in our experiment (260-265 W). The choice of high power outputs during cycling ${ }^{10}$ may result in attenuation of the differentiated effects of extreme pedalling cadences on the development of specific neuromuscular fatigue. Further research is required to analyse the relation between various pedalling strategies and muscular recruitment patterns specific to a short cycle-run session $(<1$ hour $)$.

The analysis of movement patterns during the cycle-run sessions also indicates that possible changes in muscle activity may be associated with modifications in kinematic variables. ${ }^{3}$ Hausswirth et al ${ }^{3}$ reported significant variations in stride rate-stride length combination during a run session subsequent to a cycling bout compared with an isolated run. These modifications were attributed to local muscle fatigue from the preceding cycle. In the present study, the absence of significant differences in stride pattern during running (fig 2), regardless of the prior cadence selection, indicates that there is no relation between stride pattern and running time to fatigue. These results are consistent with previous results from a laboratory setting where the running speed was fixed on a treadmill after various cadence selections. ${ }^{5}$ In contrast, in field based investigations, in which the running speed and stride pattern were freely selected by the athletes, Gottshall and Palmer ${ }^{2}$ found that cycling at $109 \mathrm{rpm}$, compared with 71 and $90 \mathrm{rpm}$, during a 30 minute cycle session resulted in an increased stride rate and running speed during a $3200 \mathrm{~m}$ track session. However, these results are in contrast with those of Bernard et $a l^{6}$ indicating an effect of the prior cadence on stride pattern only during the first $500 \mathrm{~m}$ and not during the overall $3000 \mathrm{~m}$ run. The relation between stride pattern, cycling cadence, and running performance is not clear. Further investigation is required to elucidate the mechanisms that affect running performance during a cycle-run session.

In conclusion, this study shows that the choice of a low cadence during the final minutes of cycling improves subsequent running time to fatigue. The findings suggest 
that metabolic responses related to $\mathrm{VO}_{2}$ do not explain the differences in running time to fatigue. However, the effect of cadence selection during the final minutes of cycling on muscular activity requires further investigation. From a practical standpoint, the strategy to adopt a low cadence before running, resulting in a lower metabolic load, may be beneficial during a sprint distance triathlon.

\section{ACKNOWLEDGEMENTS}

We gratefully acknowledge all the triathletes who took part in the experiment for their great cooperation and motivation.

\section{Authors' affiliations}

F Vercruyssen, J Brisswalter, Department of Sport Ergonomics and Performance, University of Toulon-Var, BP 132, 83957 La Garde cedex, France

R Suriano, D Bishop, School of Human Movement and Exercise Science, University of Western Australia, Crawley, WA 6009, Australia

C Hausswirth, Laboratory of Physiology and Biomechanics, Nationale Institute of Sport and Physical Education, 11, avenue du Tremblay, 75 012 Paris, France

Competing interests: none declared

\section{REFERENCES}

1 Bentley DJ, Millet GP, Vleck VE, et al. Specific aspects of contemporary triathlon: implications for physiological analysis and performance. Sports Med 2002;32:345-59.

2 Gottshall JS, Palmer BM. The acute effects of prior cycling cadence on running performance and kinematics. Med Sci Sports Exerc 2002;34:1518-22.

3 Hausswirth C, Bigard AX, Guezennec CY. Relationships between mechanics and energy cost of running at the end of a triathlon and a marathon. Int J Sports Med 1997; 18:330-9.

4 Hausswirth $C$, Lehénaff $D$, Dréano $P$, et al. Effects of cycling alone or in a sheltered position on subsequent running performance during a triathlon. Med Sci Sports Exerc 1999;31:599-604.

5 Vercruyssen F, Brisswalter J, Hausswirth C, et al. Influence of cycling cadence on subsequent running performance in triathletes. Med Sci Sports Exerc 2002;34:530-6.

6 Bernard T, Vercruyssen F, Grego F, et al. Effect of cycling cadence on subsequent $3-\mathrm{km}$ running performance in well-trained triathletes. $\mathrm{Br} J$ Sports Med 2003;37:154-8.

7 Jones SM, Passfield L. The dynamic calibration of bicycle power measuring cranks. In: Haake Si, eds. The engineering of sport. Oxford: Blackwell Science, 1998:265-74.

8 Bishop D, Jenkins DG, Mackinnon LT. The relationship between plasma lactate parameters, $W_{\text {peak }}$ and endurance cycling performance. Med Sci Sports Exerc 1998; 30:1270-5.

9 Lepers R, Millet GY, Maffiuletti NA, et al. Effect of pedalling rates on physiological response during endurance cycling. Eur J Appl Physiol 2001;85:392-5.
10 Lepers R, Millet GY, Maffiuletti NA. Effect of cycling cadence on contractile and neural properties of knee extensors. Med Sci Sports Exerc $2001 ; 33: 1882-8$

11 Avogadro P, Dolenec A, Belli A. Changes in mechanical work during severe exhausting running. Eur J Appl Physiol 2003;90:165-70.

12 Billat VL, Richard $\mathrm{R}$, Binsse VM, et al. The $\mathrm{VO}_{2}$ slow component for severe exercise depends on type of exercise and is not correlated with time to fatigue. J Appl Physiol 1998;85:2118-24.

13 Candau R, Belli A, Millet GY, et al. Energy cost and running mechanics during a treadmill run to voluntary exhaustion in humans. Eur J Appl Physiol 1998;77:479-85.

14 Borrani F, Candau R, Millet GY, et al. Is the $\mathrm{VO}_{2}$ slow component dependent on progressive recruitment of fast-twitch fibers in trained runners? J Appl Physiol 2001:90:2212-20.

15 Brandon $\amalg$. Physiological factors associated with middle distance running performance. Sports Med 1995;19:268-77.

16 Paavolainen L, Häkkinen K, Nummela A. Neuromuscular characteristics and muscle power as determinants of 5-km running performance. Med Sci Sports Exerc 1999;31:124-30.

17 Paavolainen L, Nummela A, Rusko $\mathrm{H}$, et al. Neuromuscular characteristics and fatigue during $10 \mathrm{~km}$ running. Int J Sports Med 1999;20:516-21.

18 Di Prampero PE. Factors limiting maximal performance in humans. Eur J Appl Physiol 2003;90:420-9.

19 Jones AM, McConnell AM. Effect of exercise modality on oxygen uptake kinetics during heavy exercise. Eur J Appl Physiol 1999;80:213-19.

20 Poole DC, Richardson RS. Determinants of oxygen uptake. Sports Med 1997;24:308-20.

21 Whipp BJ. The slow component of $\mathrm{O}_{2}$ uptake kinetics during heavy exercise. Med Sci Sports Exerc 1994;26:1319-26.

22 Barstow TJ. Jones AM, Nguyen PH, et al. Influence of muscle fiber type and pedal frequency on oxygen uptake kinetics of heavy exercise. J Appl Physiol 1996:81:1642-50

23 Yano T, Yunoki T, Ogata H. Relationship between the slow component of oxygen uptake and the potential reduction in maximal power output during constant-load exercise. J Sports Med Phys Fitness, 2001;41, 165-9.

24 Burnley M, Jones AM, Carter $\mathrm{H}$, et al. Effects of prior heavy exercise on phase II pulmonary oxygen uptake kinetics during heavy exercise. J Appl Physiol 2000;89:1387-96.

25 Gerbino A, Ward SA, Whipp BJ. Effects of prior exercise on pulmonary gasexchange kinetics during high-intensity exercise in humans. $J$ Appl Physiol 1996;80:99-107.

26 Schevermann BW, Hoelting BD, Noble ML, et al. The slow component of $\mathrm{O}_{2}$ uptake is not accompanied by changes in muscle EMG during repeated bouts of heavy exercise in humans. J Physiol 2001;531:245-56.

27 Gotshall RW, Baver TA, Fahmer SL. Cycling cadence alters exercise hemodynamics. Int J Sports Med 1996;17:17-21.

28 Bijker KE, De Groot G, Hollander AP. Differences in leg muscle activity during running and cycling in humans. Eur J Appl Physiol 2002;87:165-70.

29 Ericson MO, Nisell R, Arborelius UP, et al. Muscular activity during ergometer cycling. Scand J Rehabil Med 1985;17:53-61.

30 Marsh AP, Martin PE. The relationship between cadence and lower extremity EMG in cyclists and noncyclists. Med Sci Sports Exerc 1995;27:217-25.

31 Neptune RR, Kautz SA, Hull ML. The effect of pedaling rate on coordination in cycling. J Biomech 1997;30:1051-8.

32 Takaishi T, Yamamoto T, Ono TY, et al. Optimal pedaling rate estimated from neuromuscular fatigue for cyclists. Med Sci Sports Exerc 1996;28:1492-7. 